\title{
Nerve Injury Induces Gap Junctional Coupling among Axotomized Adult Motor Neurons
}

\author{
Qiang Chang, ${ }^{1}$ Alberto Pereda, ${ }^{2}$ Martin J. Pinter, ${ }^{3}$ and Rita J. Balice-Gordon ${ }^{1}$ \\ ${ }^{1}$ Department of Neuroscience, University of Pennsylvania School of Medicine, Philadelphia, Pennsylvania 19104-6074, \\ 2Department of Neurobiology and Anatomy, Medical College of Pennsylvania/Hahnemann School of Medicine, \\ Philadelphia, Pennsylvania 19129, and ${ }^{3}$ Department of Physiology, Emory University School of Medicine, \\ Atlanta, Georgia 30322
}

\begin{abstract}
Neonatal spinal motor neurons are electrically and dye-coupled by gap junctions, but coupling is transient and disappears rapidly after birth. Here we report that adult motor neurons become recoupled by gap junctions after peripheral nerve injury. One and 4-6 weeks after nerve cut, clusters of dyecoupled motor neurons were observed among axotomized, but not control, lumbar spinal motor neurons in adult cats. Electrical coupling was not apparent, probably because of the electrotonic distance between dendrodendritic gap junctions and the somatic recording location. Analyses of gap junction protein expression in cat and rat showed that the repertoire of connex-
\end{abstract}

ins expressed by normal adult motor neurons, Cx36, Cx37, Cx40, Cx43, and Cx45, was unchanged after axotomy. Our results suggest that the reestablishment of gap junctional coupling among axotomized adult motor neurons may occur by modulation of existing gap junction proteins that are constitutively expressed by motor neurons. After injury, interneuronal gap junctional coupling may mediate signaling that maintains the viability of axotomized motor neurons until synaptic connections are reestablished within their targets.

Key words: gap junction; motor neuron; skeletal muscle; nerve; connexin; axotomy; injury
In the adult mammalian nervous system, neuronal gap junctional coupling is relatively rare but is prominent among neurons in which temporally correlated activity is important for function, including among inferior olive neurons (Condorelli et al., 1998), hippocampal pyramidal neurons (MacVicar and Dudek, 1981), abducens motor neurons (Gogan et al., 1974), neurons in the mesencephalic nucleus of the trigeminal nerve (Baker and Llinas, 1971), as well as among inhibitory neurons in cerebellum (MannMetzer and Yarom, 1999). We reported previously that motor neurons are extensively electrically and dye-coupled at approximately the time of birth and that functional coupling becomes undetectable by the end of the first postnatal week, despite the persistent expression of several gap junction proteins (Fulton et al., 1980; Walton and Navarette, 1991; Chang et al., 1999). During development, gap junctional coupling may shape motor neuron activity by allowing the activity of one cell to be directly propagated to neighboring cells and/or by allowing the intercellular dissemination of second messengers or target-derived signals. Both electrical and biochemical communication may play roles in the establishment and editing of motor neuron synaptic connections within the spinal cord and with muscle fiber targets (for review, see Frank, 1993). Although the functional roles of motor neuron gap junctional coupling during development are poorly

Received Aug. 18, 1999; revised Oct. 25, 1999; accepted Nov. 3, 1999.

This work was supported by National Institutes of Health Grant NS34373, Spinal Cord Research Foundation of Paralyzed Veterans of America Grant 1472, and a McKnight Neuroscience Scholar award to R.B.-G. We thank Drs. M. Koval, B. Nicholson, D. Paul, and S. Scherer for connexin-specific antibodies, and Drs. M. Gonzalez, D. Kopp, K. Personius, and M. Rich for helpful discussions and comments on earlier versions of this manuscript.

Correspondence should be addressed to Rita J. Balice-Gordon, Department of Neuroscience, University of Pennsylvania School of Medicine, 215 Stemmler Hall, Philadelphia, PA 19104-6074. E-mail: rbaliceg@mail.med.upenn.edu.

Copyright (C) 2000 Society for Neuroscience 0270-6474/00/200674-11\$15.00/0 understood, it seems likely that the disappearance of coupling is one of several events that contribute to the maturation of spinal cord circuitry that, in adults, allows for the orderly recruitment of motor units during muscle force generation (for review, see Cope and Pinter, 1995).

Adult motor neurons survive for long times after peripheral axotomy (cf. Carlson et al., 1979) but undergo several changes that, in some respects, result in motor neurons resuming an immature phenotype (for review, see Titmus and Faber, 1990). These include changes in gene expression, particularly of genes encoding metabolic and cytoskeletal proteins, remodeling of dendritic branches, removal of some synaptic inputs, and changes in passive and active membrane electrical properties (Gustafsson and Pinter, 1984; Pinter and Vanden Noven, 1989; Koliatsos et al., 1990; Funakoshi et al., 1993; Wu, 1996). It was thus of interest to determine whether gap junctional coupling, widespread among developing motor neurons, was also reestablished among axotomized adult motor neurons.

Intracellular recording and iontophoretic injection of Neurobiotin, a low molecular mass compound known to pass across gap junctions, into identified motor neurons was used to show that axotomized motor neurons, but not uninjured motor neurons, become coupled by gap junctions after nerve injury. Molecular analyses of gap junction protein expression showed that the repertoire of connexins expressed by normal adult motor neurons is unchanged after axotomy. Together, our results suggest that the reestablishment of gap junctional coupling among axotomized adult motor neurons may occur by modulation of existing gap junction proteins.

Parts of this paper have been published previously in abstract form (Balice-Gordon et al., 1996; Chang and Balice-Gordon, 1997). 


\section{MATERIALS AND METHODS}

Axotomy. Adult cats were used for physiological characterization of motor neurons because of the relative ease of obtaining lengthy and stable intracellular recordings in vivo compared with other model systems. All procedures were conducted in accordance with approved protocols. Under general anesthesia [ketamine $(99 \mathrm{mg} / \mathrm{ml})$ plus acepromazine $(1 \mathrm{mg} / \mathrm{ml})$, injected intramuscularly], the left politeal fossa of adult cats $(2-4 \mathrm{~kg})$ of either gender was exposed, the medial and/or lateral gastrocnemius/soleus muscle nerves was located and severed, and a $2-3 \mathrm{~mm}$ piece of nerve was resected to prevent reinnervation. After closure of incisions in layers, the animal was allowed to recover and was returned to standard caging.

For rat experiments in which connexin expression was analyzed, adult female rats (Sprague Dawley, 9-12 weeks of age) were anesthetized with an intraperitoneal injection of Nembutal $(10-20 \mathrm{mg} / \mathrm{kg})$. The left sciatic nerve was exposed through a skin incision, severed just below the sciatic notch, and a 2-3 $\mathrm{mm}$ piece was resected. The skin was sutured with $6-0$ silk, and the animal was allowed to recover. Two weeks later, animals were killed with Nembutal (30-40 mg/kg) and transcardially perfused with PBS, followed by $4 \%$ paraformaldehyde in PBS. The L3-L6 segments of control and axotomized spinal cord were dissected and processed for reverse transcription (RT)-PCR, in situ hybridization, or immunohistochemistry.

Acute spinal cord preparation. One to 4-6 weeks after axotomy, cats were anesthetized with Nembutal $(40-45 \mathrm{mg} / \mathrm{kg}$ initial dose; supplemented as needed during experiments to eliminate corneal and pinch withdrawal reflexes). Arterial blood pressure, end-tidal $\mathrm{CO}_{2}$, and rectal temperature were monitored throughout the experiment and were maintained at above $80 \mathrm{mmHg}, 4 \%$, and $36-37^{\circ} \mathrm{C}$, respectively. Bilateral pneumothorax was routinely performed to reduce respiratory movements.

A laminectomy was made from L4 to L7 and the L4, L5, and L6 dorsal roots were cut. The axotomized medial gastrocnemius, lateral gastrocnemius-soleus nerves were dissected free from surrounding tissue and were mounted on bipolar silver wire stimulating electrodes. The hamstring, plantaris, common peroneal, and posterior tibial nerves were also dissected and prepared for stimulation. All exposed tissues were covered in warmed mineral oil. An antidromic volley elicited by nerve stimulation could be recorded from the lateral surface of the exposed spinal cord using a monopolar ball electrode. The minimum stimulation intensity required to evoke this volley was defined as threshold; subsequent stimulation was expressed in multiples of this threshold (50 $\mu$ sec pulses).

During each experiment, initial intracellular recordings from motor neurons were obtained from L6-L7 using glass micropipettes $(1-2 \mu \mathrm{m}$ tips; resistance, 5-10 M $\Omega$ ) filled with $3 \mathrm{M} \mathrm{KCl}$. Motor neurons were identified by the presence of an antidromic action potential after stimulation of a peripheral nerve. Only motor neurons with stable resting potentials greater than $-60 \mathrm{mV}$ and action potential amplitudes greater than $80 \mathrm{mV}$ were studied further. All records were stored digitally and were displayed, measured, and analyzed using interactive software.

After determining that stable intracellular recording was available, some motor neurons were iontophoretically injected (400 msec square pulses, 5-10 nA intensity, $1 \mathrm{~Hz}$ for 20-60 min) with $10 \%$ Neurobiotin (Vector Laboratories, Burlingame, CA) in $2.5 \mathrm{M} \mathrm{KCl}$ and $10 \mathrm{~mm}$ HEPES, $\mathrm{pH}$ 7.4. After a minimum of $2 \mathrm{hr}$ for dye diffusion, animals were killed and transcardially perfused with PBS, followed by $4 \%$ paraformaldehyde in PBS. The time elapsed between injection and fixation, and the extent of transcardial perfusion, were similar between control and axotomized animals. No systematic difference in the number of dye-labeled cells was observed in cases in which motor neurons were successfully injected early in an experiment compared with at the end of an experiment. Fiduciary marks were made on the spinal cord in situ before dissection from the vertebral column.

Neurobiotin histochemistry. Spinal cords were post-fixed for $4 \mathrm{hr}$ and rinsed in PBS for 8-12 hr, and vibratome sections $(50-100 \mu \mathrm{m})$ were collected into PBS. Neurobiotin histochemistry was performed as described by Chang et al. (1999). Briefly, sections were permeabilized in $100 \% \mathrm{MeOH}$ at $-20^{\circ} \mathrm{C}$, rinsed in PBS, and incubated in $50 \mu \mathrm{g} / \mathrm{ml}$ fluorescein-conjugated streptavidin (Molecular Probes, Eugene, OR) with shaking at $4^{\circ} \mathrm{C}$ overnight. After rinsing in PBS, sections were mounted on slides in an antifading medium (VectaShield; Vector Laboratories), and slides were stored at $4^{\circ} \mathrm{C}$ in the dark. Sections were imaged and analyzed using a confocal microscope (TCS-4D system; Leica, Nussloch, Germany) and interactive software. In some cases, sections were reacted for Neurobiotin using HRP-conjugated streptavidin, followed by a chromogenic reaction for HRP (Vector Laboratories), were cleared in alcohol to xylene, mounted in Permount, analyzed using transmitted light and Nomarski optics (Leica DMR-E), and were photographed onto 35 $\mathrm{mm}$ slide film. No significant difference in the number of dye-labeled cells was observed between chromogenic and fluorescent methods of detection. Slides were digitally scanned into a personal computer. Digital images were enhanced in Photoshop (Adobe Systems, Mountain View, CA) and printed using a color dye-sublimation printer (Phaser 440; Tektronix, Wilsonville, OR).

RT-PCR analysis of connexin expression. Normal rat spinal cord (L3L6), the half ipsilateral or contralateral to sciatic nerve cut 2 weeks previously, were dissected, and total RNA was extracted using TRIzol (Life Technologies, Gaithersburg, MD) and treated with RNase-free DNase to remove genomic DNA. RNA was not pooled across animals. One microgram of total RNA was reverse-transcribed into first strand cDNA, using Advantage RT-for-PCR kit (Clontech, Cambridge, UK). Primers were designed for $\mathrm{Cx} 26, \mathrm{Cx} 30, \mathrm{Cx} 31, \mathrm{Cx} 31.1, \mathrm{Cx} 32, \mathrm{Cx} 33, \mathrm{Cx} 36$, $\mathrm{Cx} 37, \mathrm{Cx} 40, \mathrm{Cx} 43, \mathrm{Cx} 45, \mathrm{Cx} 46$, and $\mathrm{Cx} 50$ to amplify a unique coding region of each gene as described by Chang et al. (1999). The $25 \mu \mathrm{l} \mathrm{PCR}$ mixture contained 5-10 $\mu \mathrm{l}$ first strand cDNA, $0.8 \mu \mathrm{M}$ deoxynucleotide triphosphates, $100 \mathrm{ng}$ of each primer, $3.5 \mu \mathrm{M}$ magnesium, $2.5 \mu \mathrm{l}$ of $10 \times$ PCR buffer (Life Technologies), and $1.25 \mathrm{U}$ of Taq polymerase (Life Technologies). PCR conditions were $94^{\circ} \mathrm{C}$ for $5 \mathrm{~min} ; 94^{\circ} \mathrm{C}$ for $45 \mathrm{sec}, 55^{\circ} \mathrm{C}$ for $30 \mathrm{sec}$, and $72^{\circ} \mathrm{C}$ for $1 \mathrm{~min}$ for $35 \mathrm{cycles}$; followed by $72^{\circ} \mathrm{C}$ for $10 \mathrm{~min}$. In each case, total RNA was used as a negative control template, and cDNA from tissues known to express a particular connexin(s), such as heart, eye, skin, liver, and testis, were used as positive control templates. RT-PCR products from spinal cord and positive control tissues were analyzed using gel electrophoresis. All products were sequenced and compared with sequences in GenBank to determine their identities.

In situ hybridization. All cRNA probes were cloned by RT-PCR from rat spinal cord as described by Chang et al. (1999). The Cx36 probe consisted of the complete rat coding sequence obtained using primers described by Condorelli et al. (1998). The Cx37 probe consisted of a 422 nt fragment of rat coding sequence (nt 637-1058) (Haefliger et al., 1992). The $\mathrm{Cx}_{\mathbf{X}} 40$ probe consisted of a $308 \mathrm{nt}$ fragment rat coding sequence (nt 719-1026) (Haefliger et al., 1992). The Cx43 probe consisted of fulllength rat coding sequence obtained from Dr. D. Paul, Harvard University, Cambridge, MA (Beyer et al., 1987). The Cx45 (Schwarz et al., 1992), Cx26 (Zhang and Nicholson, 1989), and Cx32 (Paul, 1986) probes consisted of full-length rat coding sequence. Each probe recognized a single band of the expected size in Northern analysis of adult spinal cord RNA (Chang et al., 1999).

Each probe was cloned into pGEM3 (Promega, Madison, WI), and cRNA probes were transcribed and labeled with digoxigenin-UTP (Boehringer Mannheim, Indianapolis, IN) using standard methods. Fixed rat or cat spinal cord was cryoprotected, frozen in an acetone-dry ice slurry, and stored at $-80^{\circ} \mathrm{C}$. Tissues were sectioned at $20 \mu \mathrm{m}$, processed for in situ hybridization using alkaline phosphatase (AP)conjugated anti-digoxygenin and a colorimetric reaction for AP as described by Chang et al. (1999). Quantitation of the proportion of motor neurons positive for each connexin was performed by examining multiple sections from each spinal cord, using conventional light microscopy to visualize the AP chromogenic reaction product and Nomarski optics to identify motor neurons based on their large soma size, morphology, and location. Motor neurons were counted only if a nucleus was visible and were determined to be positive if they had chromogen within their cytoplasm and/or nucleus. Slides were photographed with a Hamamatsu (Bridgewater, $\mathrm{NJ}$ ) cooled color CCD camera, and images were acquired digitally using a personal computer-based image processing system (Phase 3 Imaging, Inc.). Composite images of overlapping fields were made in Adobe Photoshop.

Immunohistochemistry. Frozen tissue sections were picked up on glass slides, rinsed with PBS, blocked with $1 \%$ BSA and $0.1 \%$ TritonX-100 in PBS, and incubated with anti-Cx antibodies at 1:50-1:500 dilution at $4{ }^{\circ} \mathrm{C}$ overnight. The antibodies used were as follows: anti-Cx26 and anti-Cx43, affinity-purified anti-peptide antibodies derived in rabbit (gift of Dr. B. Nicholson, SUNY, Buffalo, NY); anti-Cx32, mouse monoclonal antibody 7C6C7, raised against amino acids $235-246$ in the $\mathrm{C}$ terminus of $\mathrm{Cx} 32(\mathrm{Li}$ et al., 1997) (gift of Dr. E. Hertzberg, Albert Einstein College of Medicine, Bronx, NY); anti-Cx40, derived in rabbits against a glutathione $S$-transferase fusion protein containing most of the unique C-terminal region of rat Cx40, and affinity purified (gift of Dr. David Paul); and anti-Cx45, derived in rabbit against the $\mathrm{C}$ terminal, cytoplasmic domain of mouse Cx45, and affinity purified (Steinberg et al., 1994) 
Figure 1. Axotomized motor neurons are extensively dye-coupled. A, Single plane projection of confocal stack of images showing a cluster of Neurobiotin-labeled motor neurons after injection of a single medial gastrocnemius motor neuron in a cat axotomized 1 week previously. Neurobiotin was revealed with HRP-conjugated streptavidin and a chromogenic reaction for HRP. There were a total of four labeled cells in this cluster, which occupied a region $214 \times 234 \times 189$ $\mu \mathrm{m}$ in the dorsoventral, mediolateral, and rostrocaudal dimensions, respectively. $B$, Single plane projection of confocal stack of images showing a single cell body and a portion of the dendritic arbor of an injected peroneous motor neuron from a cat axotomized 1 week previously. Neurobiotin was revealed with fluorescein-conjugated streptavidin (also $C-E$ ). The absence of dye coupling in nonaxotomized motor neurons in animals in which the gastrocnemius-soleus nerve had been severed argues that gap junctional coupling is only observed among injured neurons. Scale bar: $A, B, 100 \mu \mathrm{m}$. $C$, Single plane projection of confocal stack of images showing a cluster of Neurobiotin-labeled motor neurons after injection of a single medial gastrocnemius motor neuron in a cat axotomized 4 weeks previously. There were a total of four labeled cells in this cluster, which occupied a region $260 \times 220 \times 125 \mu \mathrm{m}$ in the dorsoventral, mediolateral, and rostrocaudal dimensions, respectively. $D$, Single plane projection of confocal stack of images showing a single cell body and a portion of the dendritic arbor of an injected, nonaxotomized peroneous motor neuron from a cat axotomized 4 weeks previously. The absence of dye coupling in nonaxotomized motor neurons in animals in which the gastrocnemius-soleus nerve had been severed argues that gap junctional coupling is only observed among injured neurons, even at long times after axotomy. Scale bar: $C-E, 100 \mu \mathrm{m}$. $E$, Single plane projection of confocal stack of images showing a single cell body and a portion of the dendritic arbor of an injected medial gastrocnemius motor neuron from a normal adult cat, showing the absence of dye coupling. $F$, Summary of the number of Neurobiotin-labeled cells per cluster in normal spinal cord in spinal cord 1 and 4-6 weeks after axotomy ( filled circles) and in nonaxotomized motor pools in spinal cord 1 and 4-6 weeks after axotomy (open circles).

(gift of Dr. M. Koval, University of Pennsylvania School of Medicine, Philadelphia, PA). Negative control experiments were performed by preincubating the anti-Cx45 antibody with the peptide antigen before incubation with embryonic day 15 , postnatal day 1 , and adult rat spinal cord sections; at each of these ages, no immunostaining was observed. Similar results were obtained with a second $\mathrm{Cx} 45$ antibody (Chemicon, Temecula, CA). The specificity of each antibody used was determined by Western analysis as described by Chang et al. (1999). In some experiments, sections were also stained with anti-neurofilament antibody (SMI31; Sternberger Monoclonals Inc., Exeter, UK) and a fluorescently conjugated secondary antibody to facilitate identification of motor neurons. The light fixation conditions optimal for anti-connexin antibodies were incompatible with the heavy fixation conditions for optimal visualization of Neurobiotin, precluding double labeling. Slides were washed with PBS, incubated with appropriate fluorescent secondary antibodies at $4^{\circ} \mathrm{C}$ for 3-4 hr, washed with PBS, and coverslipped in a glycerol-based antifading medium (VectaShield; Vector Laboratories).

Slides were examined using the appropriate fluorescence filter sets on a confocal microscope (Leica TCS-4D) equipped with Nomarski optics, which facilitated identification of weakly stained or negative cells. Motor neurons were identified on the basis of their large soma size, morphology, and location, and were evaluated only if a nucleus was visible. Motor neurons were determined to be immunopositive for a particular connexin if diffuse or punctate fluorescence was visible within the cytoplasm and/or if punctate immunoreactivity was observed outlining the motor neuron soma and/or primary dendrites. Images were processed using Adobe Photoshop and printed on a color printer (Tektronix Phaser 440).

\section{RESULTS}

\section{Dye coupling is reestablished among axotomized motor neurons}

Neurobiotin, a low molecular weight compound that passes across gap junctions (Kita and Armstrong, 1991) was injected into single identified motor neurons from normal animals $(n=6$ cells from
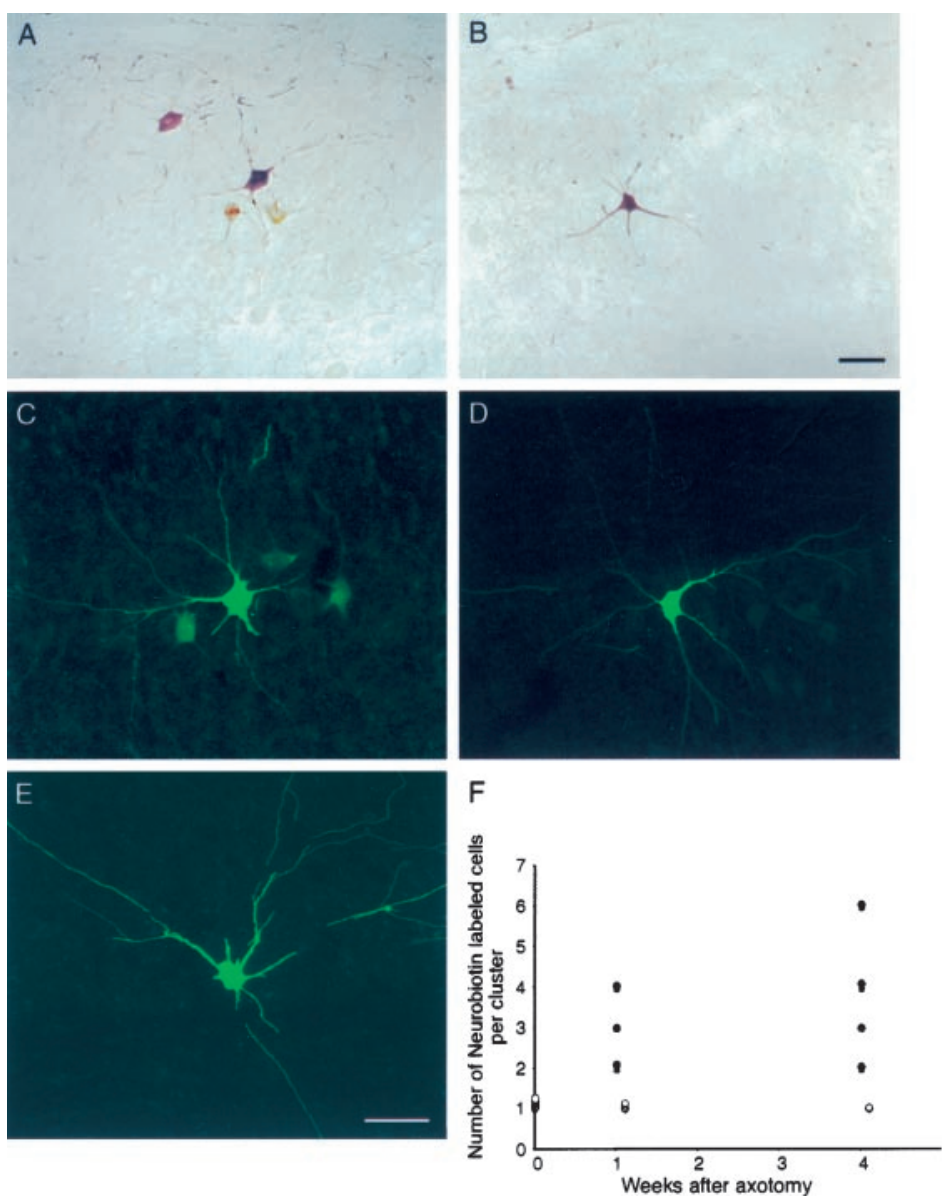

three cats) and from animals in which the medial gastrocnemius and/or lateral gastrocnemius-soleus muscle nerves were cut 1 week ( $n=6$ axotomized cells and 4 nonaxotomized cells from three cats) or 4-6 weeks ( $n=8$ axotomized cells and 2 nonaxotomized cells from five cats) previously. Based on initial experiments in which one motor neuron was injected per spinal cord and the compact nature of the resulting clusters of dye-labeled cells (see below), the minimum distance between injection sites was $2 \mathrm{~mm}$. Medial and lateral gastrocnemius-soleus motor neurons were identified by the presence of an antidromic action potential after stimulation of those muscle nerves proximal to the cut site. Nonaxotomized motor neurons innervating the tibialis anterior, plantaris, or peroneus muscles were similarly identified. After waiting a minimum of $2 \mathrm{hr}$ to allow dye to diff use from one cell to another, spinal cords were fixed, sectioned, and stained with either HRP- or fluorochrome-conjugated streptavidin and processed accordingly. Sections were then examined with light or confocal epifluorescence microscopy, and the number and the spatial distribution of dye-labeled motor neurons were determined.

In normal cat lumbar spinal cord, each of six identified gastrocnemius-soleus motor neurons injected with Neurobiotin resulted in a single robustly labeled motor neuron after histochemical processing. Injected cells showed strong Neurobiotin labeling in the cell body and throughout their extensive dendritic arbor (Fig. $1 E)$. The diameter of injected cells was $42-55 \mu \mathrm{m}$, consistent with the diameter of cat triceps surae $\alpha$ motor neurons reported previously (cf. Burke et al., 1982; Ulfhake and Kellerth, 1982). In three of these cells, a Neurobiotin-labeled axon that exited a 
Table 1. Characterization of dye coupling among axotomized motor neurons

\begin{tabular}{|c|c|c|c|c|}
\hline Weeks after axotomy $^{\mathrm{a}}$ & $\begin{array}{l}\text { Number of motor } \\
\text { neurons characterized } \\
\text { by collision test } \\
\text { (cells/animals) }\end{array}$ & $\begin{array}{l}\text { Number of dye-labeled } \\
\text { cells per cluster } \\
\text { mean } \pm \operatorname{SEM}(n), \\
\text { range }\end{array}$ & $\begin{array}{l}\text { Diameter of dye-labeled } \\
\text { cells per cluster } \\
\text { mean } \pm \text { SEM, } \\
\text { range }\end{array}$ & $\begin{array}{l}\text { Distribution of dye-labeled } \\
\text { cells rostrocaudal/dorsoventral/ } \\
\text { mediolateral } \\
\text { mean }(\mu \mathrm{m}), \\
\text { range }\end{array}$ \\
\hline \multirow[t]{2}{*}{0} & \multirow[t]{2}{*}{$17 / 4$} & $1(4)$ & $46 \pm 2$ & \multirow[t]{2}{*}{ Not applicable } \\
\hline & & Not applicable & $42-55$ & \\
\hline \multirow[t]{2}{*}{1} & \multirow[t]{2}{*}{$15 / 3$} & $2.8 \pm 0.4(6)$ & $43 \pm 2$ & $275 / 225 / 150$ \\
\hline & & $2-4$ & $40-53$ & $230-325 / 190-280 / 120-185$ \\
\hline \multirow[t]{2}{*}{$4-6$} & \multirow[t]{2}{*}{$33 / 5$} & $3.8 \pm 0.6(8)^{b}$ & $42 \pm 3$ & $230 / 205 / 135$ \\
\hline & & $2-6$ & $39-48$ & $190-270 / 180-230 / 95-160$ \\
\hline
\end{tabular}

${ }^{a}$ The medial gastrocnemius and lateral gastrocnemius-soleus muscle nerves were cut near their entry into the muscle, and a $2-3$ mm piece was resected.

${ }^{b}$ Not significantly different from value at 1 week; $p<0.10$; Student's $t$ test.

ventral root was observed. The presence of an antidromic action potential after stimulation of the gastrocnemius-soleus muscle nerves and the presence of labeled axons in the ventral root confirm that these injected cells were motor neurons, and their large soma diameter and dendritic morphology suggests that they are $\alpha$ motor neurons. These results show that, in normal adult cats, lumbar spinal motor neurons are not dye-coupled.

In contrast, 1 week after axotomy of the medial gastrocnemius and/or lateral gastrocnemius-soleus muscle nerves, Neurobiotin injection into an axotomized gastrocnemius motor neuron resulted in a single robustly labeled motor neuron (six of six cells), as well as other, more faintly labeled cells (Fig. $1 A$ ). Clusters of Neurobiotin-labeled cells contained $2.8 \pm 0.4$ cells per cluster (mean \pm SEM) (Table 1). Each labeled cell had a soma diameter ranging from 40 to $53 \mu \mathrm{m}$ (Table 1), and in many cases primary and secondary dendrites were also labeled. Based on the large soma diameters and dendritic morphology of dye-labeled cells, injected axotomized motor neurons were dye-coupled to other motor neurons, and these are likely to be $\alpha$ motor neurons.

The distribution of dye-labeled motor neurons was spatially restricted within the lateral columns of the ventral horn, in the position of the gastrocnemius-soleus motor pool. One week after axotomy, each dye-labeled cluster of motor neurons occupied a mean volume of $275 \times 225 \times 150 \mu \mathrm{m}$ in the rostrocaudal, dorsoventral, and mediolateral dimensions of the dorsolateral ventral horn, respectively (Table 1). The dimensions of individual retrogradely labeled motor pools in the cat are more than threefold as large (Romanes, 1951), which suggests that labeled motor neurons are likely within the same motor pool. In no instances were the somas of labeled motor neurons observed in direct contact with other labeled somas, and in all cases, unlabeled motor neuron somas could be observed between labeled somas (Fig. 1). These observations suggest that dye coupling occurs via dendrodendritic contact.

Nonaxotomized motor neurons innervating other skeletal muscles (such as tibialis anterior, plantaris, or peroneus) were also injected in the same animals in which the gastrocnemius-soleus nerves had been severed previously ( $n=4$ cells from three cats). Each motor neuron was identified by the presence of an antidromic action potential after muscle nerve stimulation. In each of these four cells, Neurobiotin injection resulted in a single robustly labeled motor neuron (Fig. 1B). This result shows that dye coupling is present only among axotomized motor neurons.

Four to 6 weeks after gastrocnemius-soleus nerve cut, in eight of eight cells, injection of a single motor neuron resulted in dye labeling of clusters of motor neurons that contained $3.8 \pm 0.6$ labeled cells (mean \pm SEM) (Fig. 1, Table 1). This number is not significantly higher than that observed 1 week after axotomy $(p<$ 0.10 ; Student's $t$ test), showing that the extent of dye coupling does not increase over time after nerve damage. Similar to 1 week after axotomy, all Neurobiotin-labeled cells had large diameters (39-48 $\mu \mathrm{m})$ (Table 1) and extensive dendritic arbors (Fig. 1C), suggesting that coupled cells were $\alpha$ motor neurons. Each dyelabeled cluster of motor neurons was compact, occupying a mean volume of $230 \times 205 \times 135 \mu \mathrm{m}$ in the rostrocaudal, dorsoventral, and mediolateral dimensions of the ventral horn, respectively (Table 1). This is similar to the distribution observed at 1 week after axotomy and suggests that dye coupling is present primarily among axotomized motor neurons that innervated the gastrocnemius-soleus muscle complex.

In cats axotomized 4-6 weeks previously, Neurobiotin injection of two nonaxotomized, control motor neurons innervating other skeletal muscles, identified by the presence of an antidromic action potential after muscle nerve stimulation, resulted in a single robustly labeled motor neuron (Fig. 1D). These data suggest that, even with long times after axotomy, dye coupling is present only among axotomized motor neurons.

Two control experiments were performed to rule out dye uptake that might have artifactually resulted in more than one motor neuron becoming labeled by Neurobiotin. In two nonaxotomized spinal cords, Neurobiotin was iontophoretically deposited extracellularly into the ventral horn at the location where extracellular field potentials were identified after antidromic ventral root stimulation. In none of these cases was intracellular labeling of motor neurons or other cells observed, although in some sections nonspecific labeling of capillaries was present.

We also evaluated whether Neurobiotin leaking out of the intracellular electrode, or being inadvertently iontophoresed as intracellular current was injected for physiological characterization of electrical coupling, could result in motor neuron dye labeling. This might have resulted in a cluster being observed in the absence of bona fide dye coupling. In two control and one axotomized spinal cords, four to five motor neurons were impaled and characterized with a Neurobiotin-filled intracellular electrode, but Neurobiotin was not intentionally iontophoresed. In none of these cases were dye-labeled motor neurons or other cells detected. The results of these control experiments suggest that the clusters of dye-labeled motor neurons that were observed in axotomized motor pools were attributable to intercellular gap junctional communication, as opposed to artifactual dye labeling. 


\section{Electrical coupling among axotomized motor neurons was undetectable}

After motor neurons were identified by the presence of an antidromic action potential after muscle nerve stimulation, two tests were used to determine whether the impaled motor neuron might be electrically coupled to other motor neurons $(n=17$ cells from four normal cats; $n=15$ axotomized and 5 nonaxotomized motor neurons from three cats 1 week after axotomy; $n=33$ axotomized and 10 nonaxotomized motor neurons from five cats $4-6$ weeks after axotomy). In the first test, we monitored intracellular responses to subthreshold nerve stimulation. In other systems, including neonatal motor neurons (Fulton et al., 1980; Walton and Navarette, 1991; Chang et al., 1999), this approach has revealed antidromically evoked depolarizations of several millivolts with stimulation below threshold for eliciting antidromic action potentials (Korn et al., 1977). However, no subthreshold antidromically evoked depolarizations were observed in any of the axotomized or nonaxotomized motor neurons we characterized.

The second test was a "collision test" (Baker and Llinas, 1971; Connors et al., 1983; Llinas and Sasaki, 1989). This method has been used successfully to detect the presence of coupling potentials in neonatal motor neurons (Fulton and Walton, 1986; Walton and Navarette, 1991; Chang et al., 1999), among others. Intracellular current injection was used to elicit an orthodromic action potential in the impaled motor neuron during antidromic muscle nerve stimulation. By decreasing the interval between orthodromic and antidromic stimulation, the antidromic action potential failed to invade the motor neuron soma and dendrites, and an initial segment spike was often observed. As the stimulation interval was decreased further, the initial segment spike also failed (Fig. 2). Any remaining depolarizing potential is a putative electrical coupling potential, evoked in the impaled cell by antidromic stimulation of other motor axons within the same ventral root. No depolarizing potentials were detected with this method in axotomized or nonaxotomized motor neurons.

Finally, to test the possibility that coupling is established between axotomized and nonaxotomized motor neurons, a number of other muscle nerves (e.g., tibialis, peroneus, and extensor digitorum longus) were antidromically stimulated at two to five times threshold while recording from an identified, axotomized gastrocnemius-soleus motor neuron. As above, no depolarizing potentials were detected with this method in any of the motor neurons that were characterized.

After careful evaluation using these criteria, electrical coupling potentials were not detected in normal motor neurons, in axotomized motor neurons 1 or 4-6 weeks after gastrocnemius-soleus muscle nerve cut, or in nonaxotomized motor neurons in axotomized cats. These results suggest that either electrical coupling is weak, restricted to small clusters of motor neurons (as suggested by dye-labeling experiments) or coupling potentials are electrotonically attenuated from the site of their generation to the soma, precluding their detection with these methods.

\section{The repertoire of gap junction proteins expressed by motor neurons is unchanged after axotomy}

Given that gap junctions are comprised of members of a multigene family, called connexins, with 13 members in rodents, RTPCR analysis was performed to screen for the repertoire of gap junction proteins expressed in adult spinal cord. Rodent tissue was used for these experiments because, to the best of our knowledge, no feline connexins have been cloned and sequenced to date. RNAs were isolated from normal lumbar spinal cord

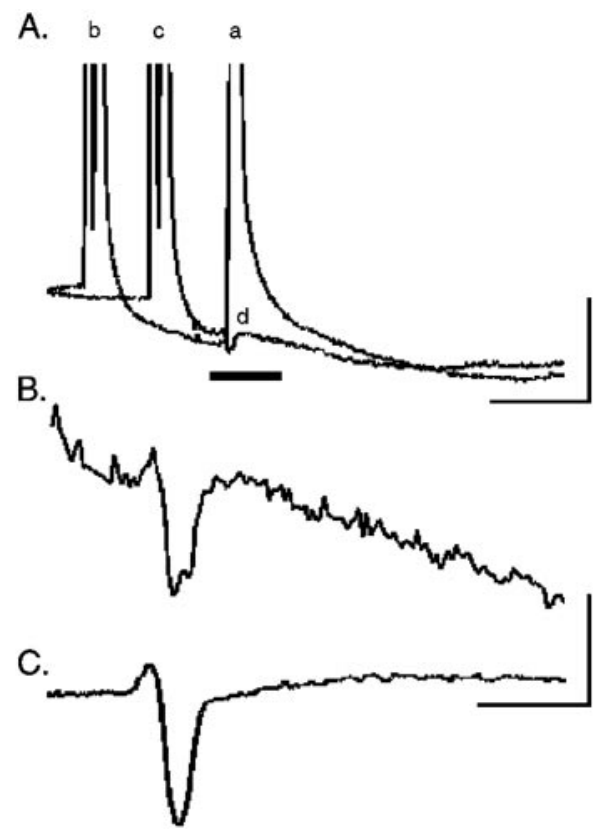

Figure 2. Electrical coupling among axotomized motor neurons is undetectable. Motor neurons were identified by intracellular impalement in cat spinal cord by the presence of an antidromic action potential $(A, a)$ after muscle nerve stimulation. $A$, Intracellular current injection was used to elicit an orthodromic action potential $(b)$ in the impaled motor neuron. By decreasing the interval between antidromic and orthodromic stimulation $(c)$, the antidromic action potential elicited by ventral root stimulation failed $(d)$. This failure occurs by collision of the antidromic spike by the intracellularly evoked action potential, which transiently inactivates voltage-gated sodium channels. Calibration: $10 \mathrm{mV}, 5 \mathrm{msec} . B$, The region indicated by the black line in the intracellular recording in $A$ is shown at higher gain during collision. A depolarizing potential occurring within $5-10 \mathrm{msec}$ of the antidromic stimulus artifact would be a putative coupling potential, but such potentials were not consistently observed. $C$, Extracellularly recorded field potential after antidromic ventral root stimulation (average of 5 sweeps) was subtracted from the intracellular trace during collision $(B)$ to determine whether any remaining depolarizing potential was present. Calibration: $B, C, 2 \mathrm{mV}, 2 \mathrm{msec}$.

from adult rats and from spinal cord ipsilateral and contralateral to sciatic nerve cut 2 weeks previously ( $n=3$ animals for each) and were reverse-transcribed into cDNA. Two weeks after sciatic nerve cut was chosen as a convenient time point, given that, in cat, the extent of dye coupling did not change between 1 and 4-6 weeks after axotomy. PCR products were amplified using primers for each of the 13 known rodent connexins (Fig. 3), and in each case, PCR products were eluted from gels, cloned, and sequenced to verify their identity.

Bands of the expected size were typically observed with cDNA as a PCR template from spinal cord and positive control tissues using primers specific for Cx26, Cx32, Cx36, Cx37, Cx40, Cx43, and $\mathrm{Cx} 45$, but bands were not observed in negative control, RNA template lanes. In contrast, primers against the other known rodent connexins amplified bands of predicted size from positive control tissues known to express that particular connexin but failed to amplify the same sized band from spinal cord. No differences were observed between the connexins expressed in normal compared with spinal cord ipsilateral or contralateral to sciatic nerve cut. This suggested that there are unlikely to be major changes in the repertoire of gap junction proteins expressed in spinal cord after axotomy.

To determine whether these seven connexins were specifically 


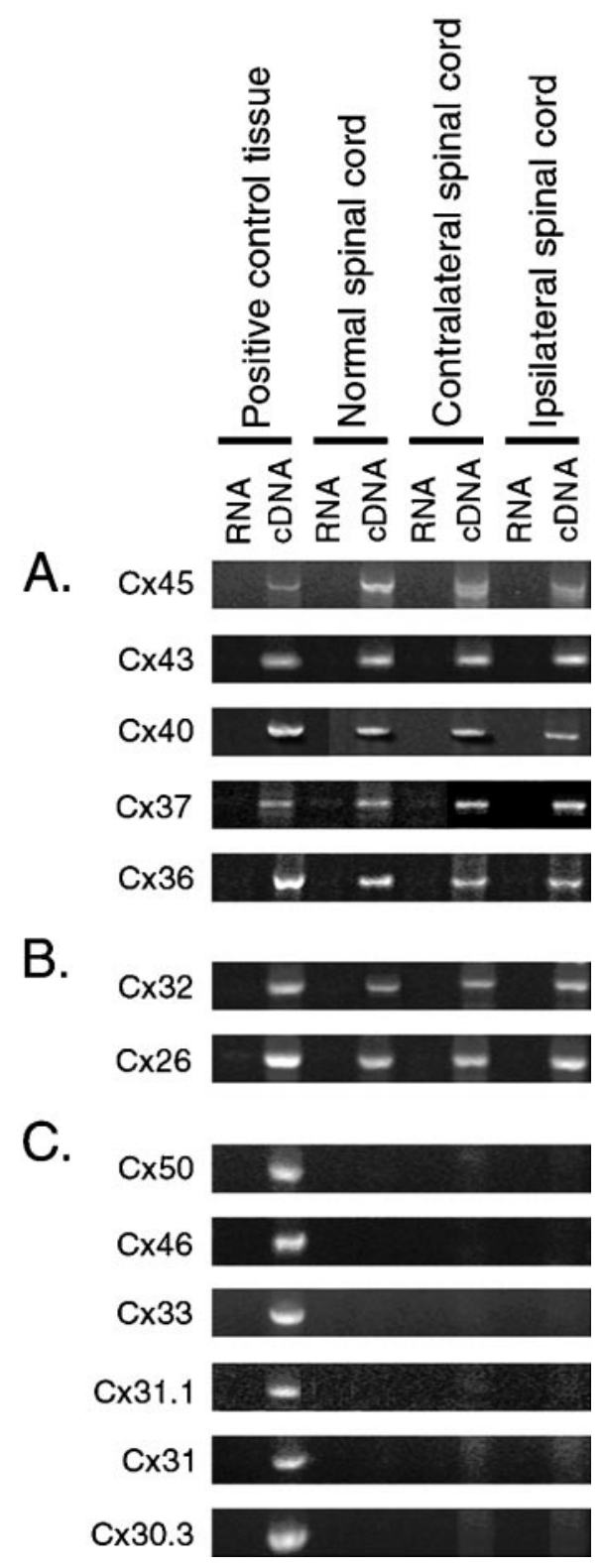

Figure 3. RT-PCR analysis of connexins expressed by normal adult and axotomized motor neurons. Using primers for each of the 13 known rodent connexins, PCR analysis was performed on cDNA from rat positive control tissues, such as heart (for Cx37, Cx40, Cx43, and Cx45), liver (for Cx26 and Cx32), eye (for Cx36, Cx46, and Cx50), skin (for Cx31.1, $\mathrm{Cx} 30.3$, and $\mathrm{Cx} 31$ ), and testis (for Cx33), normal spinal cord and spinal cord ipsilateral and contralateral to sciatic nerve cut 2 weeks previously. Corresponding RNAs were used as a negative controls. In each case, PCR products were eluted from gels, cloned, and sequenced to verify their identity. RNA was not pooled across animals, and the results shown here from one animal are representative of the other animals evaluated. $A, B$, Primers specific for Cx26, Cx32, and Cx36 amplified 364, 385, and 979 bp bands, respectively, from normal spinal cord, spinal cord contralateral and ipsilateral to sciatic nerve cut, and positive control tissue cDNA (Condorelli et al., 1998). Primers specific for Cx37, Cx40 (Haefliger et al., 1992), Cx43 (Beyer et al., 1987), and Cx45 (Schwarz et al., 1992) amplified 422, 308, 292, and 1217 bp bands, respectively, from normal spinal cord and spinal cord contralateral and ipsilateral to sciatic nerve cut and positive control tissue cDNA. Although Cx32 and Cx26 are detected by RT-PCR from spinal cord cDNA $(B)$, in situ hybridization showed that these are not expressed by motor neurons (see Fig. 4). $C$, In contrast, primers against the other known rodent connexins amplified the predicted size band from positive control tissue but failed to amplify the same sized band in spinal cord. These results suggest that the repertoire of connexins expressed in lumbar spinal cord is unchanged after axotomy. expressed in adult motor neurons and whether there were differences in expression among axotomized compared with normal motor neurons, in situ hybridization was performed with cRNA probes specific for each connexin in sections from normal rat lumbar spinal cord $(n=3)$ and from rat lumbar spinal cord 2 weeks after sciatic nerve cut $(n=3)$. Northern blot analyses of rat ventral spinal cord mRNA or positive control tissues using rodent connexin probes showed a single band of the predicted size for each connexin (Chang et al., 1999). Motor neurons were identified by their large soma size, morphology, and location.

We focused on comparing expression patterns ipsilateral and contralateral to sciatic nerve cut, in the dorsolateral and ventrolateral regions of L3-L6 rat spinal cord that contain the sciatic motor pools (Swett et al., 1986). Both ipsilaterally and contralaterally to sciatic nerve cut, Cx36, Cx37, Cx40, Cx43, and Cx45 mRNA were detected in large-diameter cells in the ventral horn (Fig. 4). The pattern of connexin expression in the ipsilateral and contralateral spinal cord of axotomized rats was strikingly similar and was also similar to that observed in unmanipulated, normal rats (Chang et al., 1999).

Although there were no gross changes in the pattern of connexin transcript expression observed after sciatic nerve cut, we determined the number of motor neurons expressing each connexin ipsilateral and contralateral to sciatic nerve cut. Motor neurons were counted only if a nucleus was visible and were determined to be positive if they had chromogen within their cytoplasm and/or nucleus. Cx36, Cx37, and Cx43 were observed to be expressed in $86-95 \%$ of lateral lumbar motor neurons, whereas $\mathrm{Cx} 45$ was expressed in $\sim 45 \%$ and $\mathrm{Cx} 40$ in $<10 \%$ of these cells (Table 2). Cx26 and Cx32 mRNA were detected in meningeal and ependymal cells and glia, as reported previously (Nadarajah et al., 1996; Kunzelmann et al., 1997; Pastor et al., 1998), but were not expressed by motor neurons (Fig. 4, bottom row).

To compare the pattern of connexin expression between axotomized and nonaxotomized rat motor neurons with axotomized and nonaxotomized cat motor neurons in which extensive dyecoupling had been observed, in situ hybridization was performed with rat connexin cRNA probes in sections from normal cat spinal cord $(n=3)$ and from spinal cord 1 week $(n=3)$ and $4-6$ weeks $(n=3)$ after axotomy. Connexins are highly conserved across species (Dermietzel and Spray, 1993; Bruzzone and Ressot, 1997). The rodent primers we used amplified connexin fragments of the expected size from cat spinal cord by RT-PCR, and rodent probes recognized connexin transcripts of the appropriate size in cat spinal cord by Northern blot analysis (data not shown).

In the cat, we focused on expression patterns in the dorsolateral and ventrolateral regions of L6-L7 spinal cord containing the gastrocnemius and soleus motor pools (Romanes, 1951). The pattern observed with each connexin probe after in situ hybridization in cat spinal cord was similar to that observed in rat for each experimental condition (Fig. 4). Cx36, Cx37, Cx40, Cx43, and $\mathrm{Cx} 45$ mRNA were detected in motor neurons, which were identified by their large soma size, distinct morphology, and location. As in rat, motor neurons were counted only if a nucleus was visible and were determined to be positive if they had chromogen within their cytoplasm and/or nucleus. Cx26 and Cx32 were detected in meningeal and ependymal cells and glia but were not detected in motor neurons. The expression of each connexin was similar on the axotomized side of the spinal cord and the contralateral, nonaxotomized side (Fig. 4). As in rat, no difference in either the pattern or proportion of positive motor neurons was observed between normal, unmanipulated spinal cord (data 
Cat

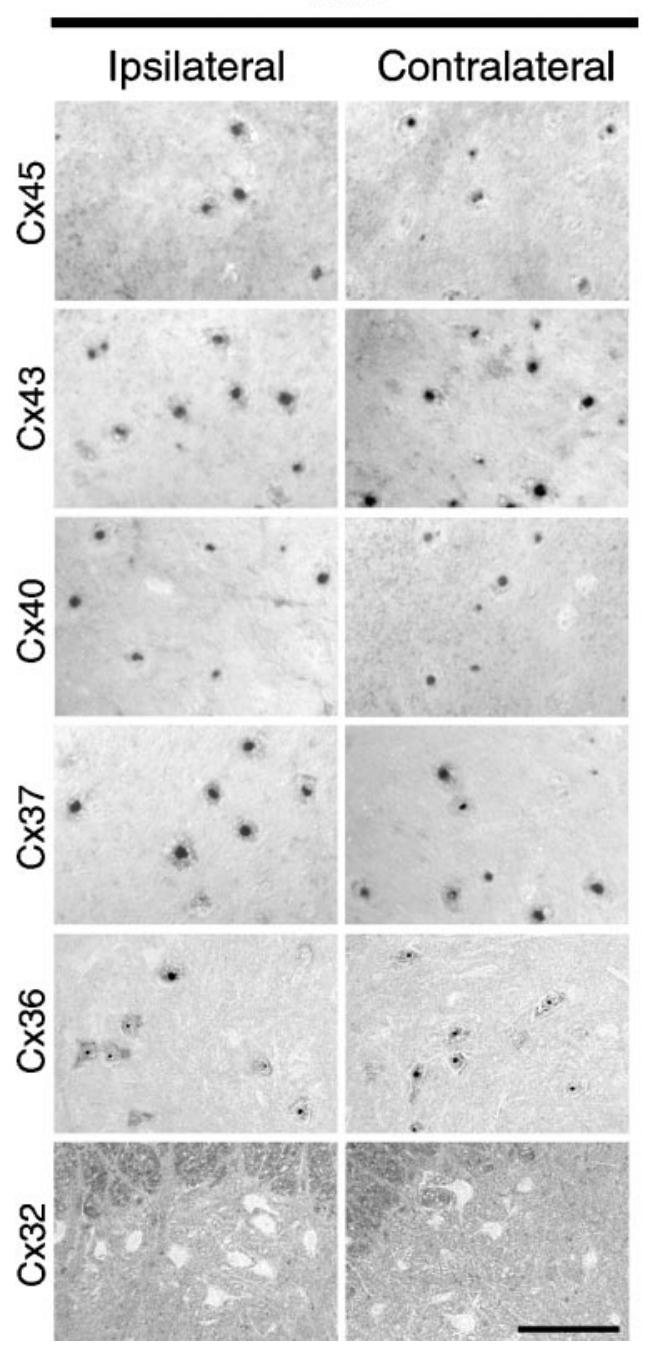

Rat

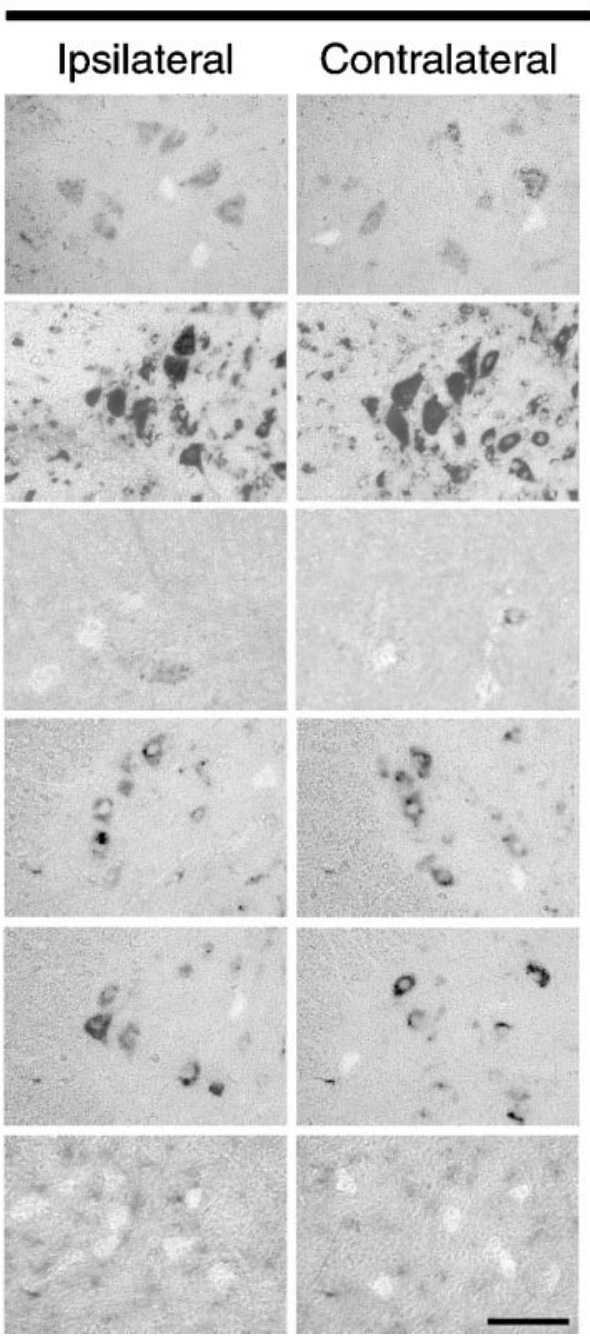

Figure 4. Connexin expression in motor neurons analyzed by in situ hybridization in rat and cat spinal cord is unchanged after axotomy. To compare the pattern of connexin expression between normal and axotomized rat motor neurons with normal and axotomized cat motor neurons in which extensive dye coupling had been characterized, in situ hybridization was performed with rat connexin cRNA probes and was visualized with a chromogenic reaction that resulted in positive cells appearing dark. Left, Shown are photographs of cat ventral L6-L7 spinal cord containing the gastrocnemius-soleus motor pools ipsilateral (left) or contralateral (left middle) to muscle nerve cut 4 weeks previously. Scale bar, $500 \mu \mathrm{m}$. Right, Shown are photographs of the lateral region of rat ventral spinal cord containing the sciatic nerve motor pools ipsilateral (right middle) or contralateral (right) to sciatic nerve cut 1 week previously. Cx45, Cx43, Cx40, Cx37, and Cx36 mRNA were detected in cat and rat motor neurons, identified by their location and large soma size. The pattern observed with each connexin probe after in situ hybridization in cat spinal cord was similar to that observed in rat for each experimental condition, with the exception that $\mathrm{Cx} 40$ was expressed in $\sim 10 \%$ of rat motor neurons compared with $\sim 75 \%$ of cat motor neurons. Neither Cx32 (bottom) or Cx26 (data not shown) were detected in motor neurons, but these were detected in meningeal and ependymal cells and glia. Scale bar, $100 \mu \mathrm{m}$. not shown) and ipsilateral and contralateral spinal cord 1 week (Fig. 4) or 4-6 weeks after axotomy (data not shown). One and 4-6 weeks after axotomy, Cx36, Cx37, and Cx43 were expressed in $\sim 78-100 \%$ of lateral lumbar motor neurons, whereas $\mathrm{Cx} 45$ was expressed in $\sim 55 \%$ and $\mathrm{Cx} 40$ in $\sim 75 \%$ of these cells (Table 2 ). We found that $\mathrm{Cx} 40$ was expressed in $\sim 75 \%$ of cat motor neurons compared with $<10 \%$ of rat motor neurons, although no differences were observed in rat or cat motor neurons ipsilateral or contralateral to nerve cut. Thus, in both rat and cat, no major changes in the proportion of motor neurons expressing gap junction mRNA are apparent when dye coupling is reestablished.

To determine whether connexin proteins are expressed in rat and cat motor neurons, immunostaining with antibodies specific for $\mathrm{Cx} 32, \mathrm{Cx} 40, \mathrm{Cx} 43$, and $\mathrm{Cx} 45$ was performed. Antibodies were characterized by Western blot analysis in spinal cord tissue, and each recognized a band of the expected molecular mass (Chang et al., 1999). As for evaluation of in situ hybridization, motor neurons were identified on the basis of their large soma size, morphology, and location and were evaluated only if a nucleus was visible. Motor neurons were determined to be immunopositive for a particular connexin if diffuse or punctate fluorescence was visible within the cytoplasm and/or if punctate immunoreac-
Table 2. Connexin transcripts expressed in axotomized compared with nonaxotomized motor neurons

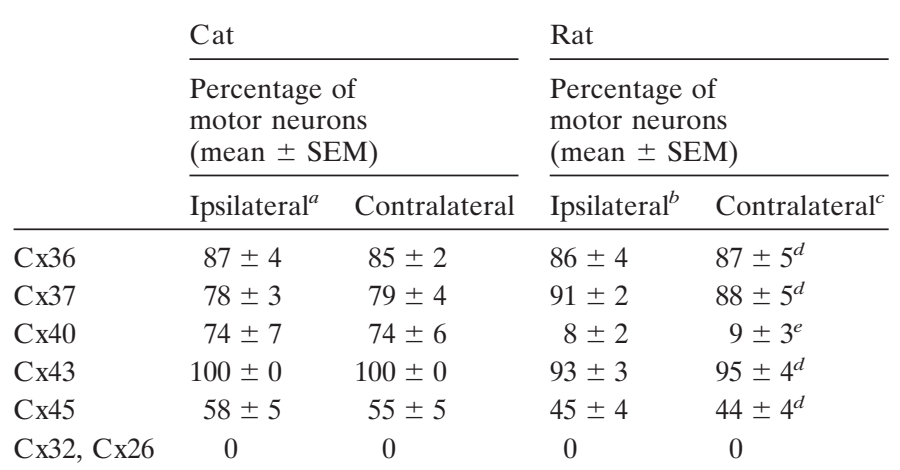

$\overline{{ }^{a} \text { Side of spinal cord ipsilateral to muscle nerve cut. Motor neurons in the medial }}$ gastrocnemius, lateral gastrocnemius, and soleus motor nuclei were evaluated in dorsolateral region of ventral horn ( $n=$ at least 3 animals).

${ }^{b}$ Side of spinal cord ipsilateral to sciatic nerve cut. Motor neurons in the dorsolateral and ventrolateral motor pools were evaluated ( $n=$ at least 3 animals).

${ }^{c}$ See also Chang et al. (1999).

${ }^{d}$ Not significantly different between rat and cat; Fisher's exact test; $p>0.100$.

${ }^{e}$ Significantly different; Fisher's exact test; $p<0.05$. 
Cat
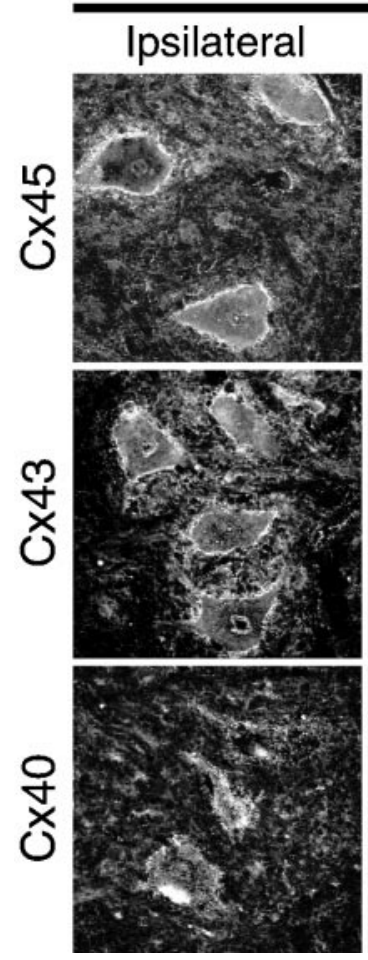

\section{Rat}
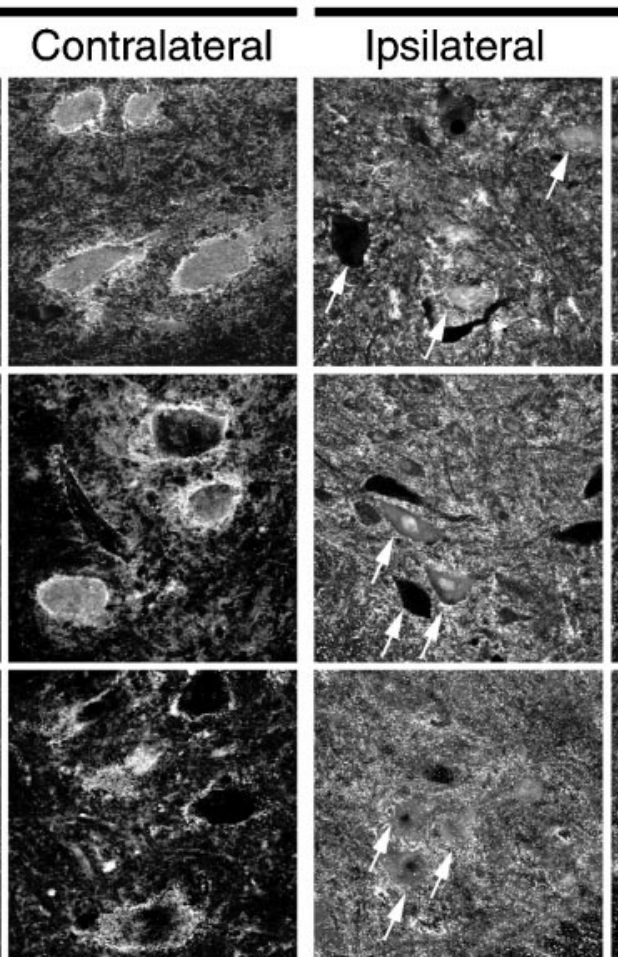

Contralateral
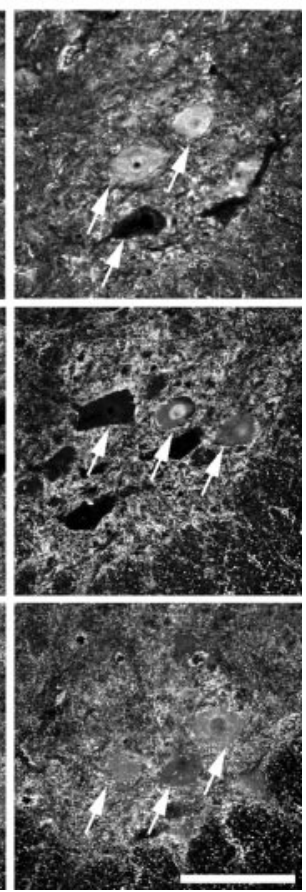

Figure 5. Connexin protein expression in motor neurons is unchanged after axotomy in rat and cat spinal cord. To determine whether connexin proteins are expressed in rat and cat motor neurons, immunostaining with antibodies specific for $\mathrm{Cx} 45, \mathrm{Cx} 43$, and $\mathrm{Cx} 40$ was performed in cat (axotomized side, left; contralateral side, left middle) and rat (axotomized side, right middle; contralateral side, right) spinal cord. Shown are single plane projections of confocal stacks of images from cat L6-L7 dorsolateral ventral spinal cord containing the gastrocnemius motor pools or rat L3-L6 lateral and ventral spinal cord containing the sciatic nerve motor pools, obtained on a Leica TCS-4D system with a $40 \times, 1.25$ NA oil immersion lens. In both rat and cat, anti-Cx45 (top row), Cx43 (middle row), and $\mathrm{Cx} 45$ (bottom row) antibodies revealed punctate staining surrounding motor neuron soma (several are indicated with arrows in each rat panel) and primary dendrites in the ventral horn. Some motor neurons had prominent cytoplasmic staining in addition to punctate, membrane-associated staining. Similar patterns of staining were observed in unmanipulated control animals (data not shown) and were similar in the spinal cord ipsilateral and contralateral to sciatic nerve cut 1 and $4-6$ weeks after axotomy. In the middle row, note the absence of a change in Cx43 protein expression in glia in and around axotomized motor neurons (but see Rohlmann et al., 1993, 1994). These results show that, in rat and in cat, axotomy does not result in a detectable change in connexin protein expression in injured motor neurons. Scale bar, $100 \mu \mathrm{m}$.

tivity was observed outlining the motor neuron soma and/or primary dendrites.

Punctate staining with anti-Cx40, Cx43, and Cx45 antibodies was detected surrounding motor neuron soma and primary dendrites in the dorsal and lateral ventral horn in both rat and cat (Fig. 5). Qualitatively similar patterns of staining were observed in unmanipulated control animals and in the spinal cord ipsilateral and contralateral to nerve cut. Quantification of the proportion of motor neurons immunopositive for each connexin was more difficult than for in situ hybridization because of the difficulty of determining whether punctate immunoreactivity was associated with motor neuron membranes as opposed to the membranes of surrounding cells, such as glia. However, using the criteria described above and in agreement with the patterns of mRNA expression observed by in situ hybridization, in rat, $\mathrm{Cx} 43$ immunoreactivity was observed in $\sim 75 \%$ of lateral lumbar motor neurons, whereas $\mathrm{Cx} 45$ and $\mathrm{Cx} 40$ immunoreactivity were observed in $\sim 40$ and $\sim 10 \%$ of these cells, respectively. Similar patterns of immunostaining were observed in cat, although somewhat more motor neurons were observed to be immunopositive for $\mathrm{Cx} 40$ in cat $(\sim 70 \%)$ than rat, consistent with the in situ hybridization results. Immunostaining with anti-Cx26 and antiCx32 antibodies revealed meningeal, ependymal, and glial cells, but motor neurons were not positive for these connexin proteins (data not shown). Together, these results show that, in rat and in cat, normal adult motor neurons express at least five connexins and that axotomy does not result in a detectable change in the repertoire of connexin expression.

\section{DISCUSSION}

Our results show that axotomized cat motor neurons become recoupled by gap junctions after peripheral nerve injury. One week after nerve cut, dye coupling was present among axotomized lumbar spinal motor neurons but not among nonaxotomized motor neurons in axotomized animals or in unmanipulated animals, and this dye coupling persisted 4-6 weeks after axotomy. Because the somas of labeled motor neurons were never observed in direct contact with other somas, dye coupling likely occurs via dendrodendritic contact. Careful physiological evaluation showed that electrical coupling was not detectable, and this is likely because of a relatively small number of dye-coupled cells and/or to the attenuation of electrical potentials from the dendrites to the site of recording in the soma. Molecular analyses of gap junction proteins were used to determine whether the reestablishment of dye coupling was accompanied by a change in gap junction protein expression. In the rat and cat, the repertoire of connexins expressed by normal adult motor neurons, Cx36, Cx37, $\mathrm{Cx} 40, \mathrm{Cx} 43$, and $\mathrm{Cx} 45$, is unchanged after axotomy. Although quantitative RT-PCR, Northern, or Western blot analyses might allow changes in the overall level of connexin expression to be evaluated, these would only be informative from purified normal and axotomized motor neurons, because other cell types within the spinal cord express an overlapping repertoire of connexins. At present, such purification is not technically feasible.

Together, our results suggest that the reestablishment of gap junctional coupling among axotomized adult motor neurons may occur by two general mechanisms. The first is that axotomy results in an increase in the number of motor neuron-motor neuron contacts with functional gap junctions, perhaps by increasing the insertion of existing connexins into motor neuron membranes. This seems plausible, given that some synaptic inputs appear to be lost from distal motor neuron dendrites after axotomy (for review, see Titmus and Faber, 1990), and this may in 
turn increase the likelihood of direct membrane-membrane interactions among dendrites. However, punctate connexin immunoreactivity was present in both axotomized and nonaxotomized motor neurons, and no qualitative increase in puncta was observed after axotomy, as might be expected if more gap junction proteins were inserted into motor neuron membranes. On the other hand, changes in puncta density along distal dendrites may occur but would be difficult to monitor by light microscopy and immunostaining.

The second possibility is that axotomy results in the modulation of existing but normally nonfunctional gap junctions that are constitutively present in motor neuron membranes, by affecting permeability, conductance, or open state. This would be consistent with ultrastructural observations of gap junction profiles along dendrites and among dendritic bundles in both normal adult cat and rat (Matthews et al., 1971; van der Want et al., 1998). van der Want et al. (1998) used retrograde labeling of adult rat soleus motor neurons with cholera toxin, followed by transmission electron microscopy, to demonstrate that gap junctions were present along proximal and distal motor neuron dendrites, confirming and extending earlier observations by Matthews et al. (1971) in cat spinal cord. Given that gap junctions are present ultrastructurally in normal rat and cat spinal cord, that five connexins capable of forming fully functional gap junctions (for review, see Kumar, 1999) are constitutively expressed by motor neurons, and that this expression is unchanged after axotomy, it seems plausible that the reestablishment of dye coupling after axotomy occurs by the modulation of existing gap junction proteins and plaques that, under normal circumstances, do not contribute to dye or electrical coupling in adult animals. Our work provides a functional and molecular context for determining how intracellular signals generated by axon damage are translated into the reestablishment of intercellular signaling and for understanding what functional roles intercellular signaling may play in the reestablishment of synaptic connectivity within the spinal cord and with muscle targets.

\section{Intercellular communication among motor neurons in development and after axotomy}

Previous work from our group and others has shown that lumbar spinal motor neurons are extensively electrically and dye-coupled by gap junctions at approximately the time of birth (Fulton and Walton, 1986; Walton and Navarrete, 1991; Chang et al., 1999). We showed previously that the percentage of dye and electrically coupled motor neurons declines rapidly in the first week after birth. The compact distribution of dye-labeled motor neurons within a cluster suggested that, at postnatal ages, coupling is spatially restricted, probably to motor neurons that innervate the same muscle.

After nerve damage, the distribution of dye-labeled, axotomized motor neurons was spatially restricted within the lateral columns of the ventral horn, in the position of the gastrocnemiussoleus motor pool. Despite the fact that there is some overlap among motor pools in the cat ventral spinal cord (Romanes, 1951), it seems likely from the distribution of dye-labeled motor neurons that dye coupling is present primarily among axotomized motor neurons that innervated the gastrocnemius-soleus muscle complex. The compact distribution of dye-labeled motor neurons, together with our finding that nonaxotomized motor neurons are not dye-coupled, strongly suggest that coupling is present only among axotomized motor neurons.

In contrast to developing motor neurons, coupling potentials were not routinely observed in axotomized adult motor neurons after a collision test. It seems likely that the inability to detect electrical coupling reflects both limited total conductance because of the small number of coupled cells and electrotonic attenuation occurring between dendrodendritic gap junctions and the somatic recording site. Given the extensive dendritic arbor of $\alpha$ motor neurons and the fact that close membrane appositions containing gap junctions are likely to exist only in the distal parts of those arbors in which overlap among the dendritic branches of different motor neurons is likely to occur, electrical potentials would likely be passively attenuated below the limit of detection by the time they reach the cell body. Gap junctions present on the intermingled distal dendrites of axotomized motor neurons might influence local synaptic events but would be unlikely to affect synaptic integration at the initial segment of the axon.

\section{Functional roles gap junctional coupling among motor neurons during development and after injury}

To the best of our knowledge, this is the first report of the reestablishment of gap junctional coupling among injured adult neurons, although changes in gap junction expression after injury or in disease states have been recognized as playing a role in recovery mechanisms (for review, see Dermietzel and Hofstadter, 1998). In liver, epidermis, and cornea, changes in connexin expression occur shortly after tissue insult (Fallon et al., 1995; Goliger and Paul, 1995; Matic et al., 1997). In the CNS, injury rapidly activates glial cells near axotomized neurons (for review, see Aldskogius and Kozlova, 1998). Astrocytes in the facial nucleus (Rohlmann et al., 1993, 1994) and surrounding the site of compression injury in spinal cord (Theriault et al., 1997) have been shown to rapidly upregulate Cx43 expression after injury. Rohlmann and colleagues (Rohlmann et al., 1993) further showed that a similar upregulation of $\mathrm{Cx} 43$ occurred in glia surrounding the central projections of peripherally injured sensory ganglion cells. We carefully examined Cx43 expression in and around the axotomized gastrocnemius and soleus motor nuclei compared with the contralateral, nonaxotomized side and with unmanipulated controls, and we did not observe a change in Cx43 immunoreactivity up to 4-6 weeks after axotomy. In the peripheral nervous system, changes in connexin expression have been observed in Schwann cells after axotomy (Chandross et al., 1996; Nagaoka et al., 1999). These results suggest that in the brain, as well as in the periphery, glia may detect signals that depend on integrity of neighboring neurons.

After damage, transient gap junctional coupling among injured motor neurons might allow electrical and/or biochemical communication that could serve several roles. Neural activity plays a critical role in the refinement of synaptic connections throughout the developing nervous system (for review, see Goodman and Shatz, 1993) and has been suggested to play a similar role during repair after injury (Ribchester, 1988; Rich and Lichtman, 1989; Barry and Ribchester, 1995). By shaping patterns of neuronal activity among coupled motor neurons, gap junctional coupling might influence the specificity with which synaptic connections are reestablished after axotomy.

Gap junctional coupling among motor neurons may be one of several mechanisms that bias motor neuron activity to be temporally correlated during the time muscle innervation is reestablished after nerve damage. This may play a role in the recapitulation of transient multiple innervation of muscle fibers (cf. Rich and Lichtman, 1989). As electrical coupling disappears, motor neuron activity may become less temporally related. This may be 
one of several mechanisms that underlies the loss of multiple innervation and results in the mature pattern of single innervation of muscle fibers. Although gap junctional coupling mediates electrical communication among some neurons, it also mediates biochemical communication (Kandler and Katz, 1998), allowing the exchange of second messengers, as well as other factors, which may directly or indirectly modulate neuronal activity. Biochemical coupling among axotomized neurons might facilitate their survival until connections can be reestablished with synaptic targets, perhaps by allowing the dissemination of signals that modulate neuron properties and survival.

\section{REFERENCES}

Aldskogius H, Kozlova EN (1998) Central neuron-glial and glial-glial interactions following axon injury. Prog Neurobiol 55:1-26.

Baker R, Llinas R (1971) Electrotonic coupling between neurones in the rat mesencephalic nucleus. J Physiol (Lond) 212:45-63.

Balice-Gordon RJ, Pereda A, Pinter MJ (1996) Functional gap junctions couple motor neurons in development and reinnervation. Soc Neurosci Abstr 22:1487.

Barry JA, Ribchester RR (1995) Persistent polyneuronal innervation in partially denervated rat muscle after reinnervation and recovery from prolonged nerve conduction block. J Neurosci 15:6327-6339.

Beyer EC, Paul DL, Goodenough DA (1987) Connexin43: a protein from rat heart homologous to a gap junction protein from liver. J Cell Biol 105:2621-2629.

Bruzzone R, Ressot C (1997) Connexins, gap junctions and cell-cell signalling in the nervous system. Eur J Neurosci 9:1-6.

Burke RE, Dum RP, Fleshman JW, Glenn LL, Lev-Tov A, O'Donovan MJ, Pinter MJ (1982) A HRP study of the relation between cell size and motor unit type in cat ankle extensor motoneurons. J Comp Neurol 209:17-28

Carlson J, Lais AC, Dyck PJ (1979) Axonal atrophy from permanent peripheral axotomy in adult cat. J Neuropathol Exp Neurol 38:579-585.

Chandross KJ, Kessler JA, Cohen RI, Simburger E, Spray DC, Bieri P, Dermietzel R (1996) Altered connexin expression after peripheral nerve injury. Mol Cell Neurosci 7:501-518.

Chang Q, Balice-Gordon RJ (1997) Developmental regulation of connexin expression in motor neurons. Soc Neurosci Abstr 23:1677.

Chang Q, Gonzalez M, Pinter MJ, Balice-Gordon RJ (1999) Gap junctional coupling and connexin expression among neonatal rat lumbar spinal motor neurons. J Neurosci 19:10813-10828.

Condorelli DF, Parenti R, Spinella F, Salinaro AT, Belluardo N, Cardile V, Cicirata F (1998) Cloning of a new gap junction gene (Cx36) highly expressed in mammalian brain neurons. Eur J Neurosci 10:1202-1208.

Connors BW, Benardo LS, Prince DA (1983) Coupling between neurons of the developing rat neocortex. J Neurosci 3:773-782.

Cope TC, Pinter MJ (1995) The size principle: still working after all these years. News Physiol Sci 10:280-286.

Dermietzel R, Hofstadter F (1998) Gap junctions in health and disease. Virchows Arch 432:177-186.

Dermietzel R, Spray DC (1993) Gap junctions in the brain: where, what type, how many and why? Trends Neurosci 16:186-192.

Fallon MB, Nathanson MH, Mennone A, Saez JC, Burgstahler AD, Anderson JM (1995) Altered expression and function of hepatocyte gap junctions after common bile duct ligation in the rat. Am J Physiol 268:C1186-C1194.

Frank E (1993) New life in an old structure: the development of synaptic pathways in the spinal cord. Curr Opin Neurobiol 3:82-86.

Fulton BP, Walton K (1986) Electrophysiological properties of neonatal rat motoneurones studied in vitro. J Physiol (Lond) 370:651-678.

Fulton BP, Miledi R, Takahashi T (1980) Electrical synapses between motoneurons in the spinal cord of the newborn rat. Proc R Soc Lond B Biol Sci 208:115-120.

Funakoshi H, Frisen J, Barbany G, Timmusk T, Zachrisson O, Verge VM, Persson H (1993) Differential expression of mRNAs for neurotrophins and their receptors after axotomy of the sciatic nerve. J Cell Biol 123:455-465.

Gogan P, Gueritaud JP, Horcholle-Bossavit G, Tyc-Dumont S (1974) Electrotonic coupling between motoneurones in the abducens nucleus of the cat. Exp Brain Res 21:139-154.

Goliger JA, Paul DL (1995) Wounding alters epidermal connexin ex- pression and gap junction-mediated intercellular communication. Mol Biol Cell 6:1491-1501.

Goodman CS, Shatz CJ (1993) Developmental mechanisms that generate precise patterns of neuronal connectivity. Neuron 10:77-98.

Gustafsson B, Pinter MJ (1984) Effects of axotomy on the distribution of passive electrical properties of cat motoneurones. J Physiol (Lond) 356:433-442.

Haefliger JA, Bruzzone R, Jenkins NA, Gilbert DJ, Copeland NG, Paul DL (1992) Four novel members of the connexin family of gap junction proteins. Molecular cloning, expression, and chromosome mapping. J Biol Chem 267:2057-2064.

Kandler K, Katz LC (1998) Coordination of neuronal activity in developing visual cortex by gap junction-mediated biochemical communication. J Neurosci 18:1419-1427.

Kita H, Armstrong W (1991) A biotin-containing compound N-(2aminoethyl)biotinamide for intracellular labeling and neuronal tracing studies: comparison with biocytin. J Neurosci Methods 37:141-150.

Koliatsos VE, Price DL, Clatterbuck RE (1990) Motor neurons in Onuf's nucleus and its rat homologues express the p75 nerve growth factor receptor: sexual dimorphism and regulation by axotomy. J Comp Neurol 345:510-527.

Korn H, Sotelo C, Bennett MVL (1977) The lateral vestibular nucleus of the toadfish Opsanus tau: ultrastructural and electrophysiological observations with special reference to electrotonic transmission. Neuroscience 2:851-884.

Kumar NM (1999) Molecular biology of the interactions between connexins. Novartis Found Symp 219:6-16.

Kunzelmann P, Blumcke I, Traub O, Dermietzel R, Willecke K (1997) Coexpression of connexin 45 and -32 in oligodendrocytes of rat brain. J Neurocytol 26:17-22.

Li J, Hertzberg EL, Nagy JI (1997) Connexin32 in oligodendrocytes and association with myelinated fibers in mouse and rat brain. J Comp Neurol 379:571-591.

Llinas R, Sasaki K (1989) The functional organization of the olivocerebellar system as examined by multiple purkinje cell recordings. Eur J Neurosci 1:587-602.

MacVicar BA, Dudek FE (1981) Electrotonic coupling between pyramidal cells: a direct demonstration in rat hippocampal slices. Science 213:782-784.

Mann-Metzer P, Yarom Y (1999) Electrotonic coupling interacts with intrinsic properties to generate synchronized activity in cerebellar networks of inhibitory interneurons. J Neurosci 19:3298-3306.

Matic M, Petrov IN, Rosenfeld T, Wolosin JM (1997) Alterations in connexin expression and cell communication in healing corneal epithelium. Invest Ophthalmol Vis Sci 38:600-609.

Matthews MA, Willis WD, Williams V (1971) Dendrite bundles in lamina IX of cat spinal cord: a possible source for electrical interaction between motoneurons? Anat Rec 171:313-327.

Nadarajah B, Thomaidou D, Evans WH, Parnavelas JG (1996) Gap junctions in the adult cerebral cortex: regional differences in their distribution and cellular expression of connexins. J Comp Neurol 376:326-342.

Nagaoka T, Oyamada M, Okajima S, Takamatsu T (1999) Differential expression of gap junction proteins connexin26, 32, and 43 in normal and crush-injured rat sciatic nerves. Close relationship between connexin43 and occludin in the perineurium. J Histochem Cytochem 47:937-948.

Pastor A, Kremer M, Moller T, Kettenmann H, Dermietzel R (1998) Dye coupling between spinal cord oligodendrocytes: differences in coupling efficiency between gray and white matter. Glia 24:108-120.

Paul DL (1986) Molecular cloning of cDNA for rat liver gap junction protein. J Cell Biol 103:123-134.

Pinter MJ, Vanden Noven S (1989) Effects of preventing reinnervation on axotomized spinal motoneurons in the cat. I. Motoneuron electrical properties. J Neurophysiol 62:311-324.

Ribchester RR (1988) Activity-dependent and -independent synaptic interactions during reinnervation of partially denervated rat muscle. J Physiol (Lond) 401:53-75.

Rich MM, Lichtman JW (1989) In vivo visualization of pre- and postsynaptic changes during synapse elimination in reinnervated mouse muscle. J Neurosci 9:1781-1805.

Rohlmann A, Laskawi R, Hofer A, Dobo E, Dermietzel R, Wolff JR (1993) Facial nerve lesions lead to increased immunostaining of the astrocytic gap junction protein (connexin 43) in the corresponding facial nucleus of rats. Neurosci Lett 154:206-208. 
Rohlmann A, Laskawi R, Hofer A, Dermietzel R, Wolff JR (1994) Astrocytes as rapid sensors of peripheral axotomy in the facial nucleus of rats. NeuroReport 5:409-412.

Romanes GJ (1951) The motor cell columns of the lumbo-sacral spinal cord of the cat. J Anat 85:313-358.

Schwarz HJ, Chang YS, Hennemann H, Dahl E, Lalley PA, Willecke K (1992) Chromosomal assignments of mouse connexin genes, coding for gap junctional proteins, by somatic cell hybridization. Somat Cell Mol Genet 18:351-359.

Steinberg TH, Civitelli R, Geist ST, Robertson AJ, Hick E, Veenstra RD, Wang HZ, Warlow PM, Westphale EM, Laing JG, Beyer EC (1994) Connexin43 and connexin 45 form gap junctions with different molecular permeabilities in osteoblastic cells. EMBO J 13:744-750.

Swett JE, Wikholm RP, Blanks RH, Swett AL, Conley LC (1986) Motoneurons of the rat sciatic nerve. Exp Neurol 93:227-252.

Theriault E, Frankenstein UN, Hertzberg EL, Nagy JI (1997) Connexin43 and astrocytic gap junctions in the rat spinal cord after acute compression injury. J Comp Neurol 382:199-214.
Titmus MJ, Faber DS (1990) Axotomy-induced alterations in the electrophysiological characteristics of neurons. Prog Neurobiol 35:1-51.

Ulfhake B, Kellerth JO (1982) Does alpha-motoneurone size correlate with motor unit type in cat triceps surae? Brain Res 251:201-209.

van der Want JJ, Gramsbergen A, Ijkema-Paassen J, de Weerd H, Liem RS (1998) Dendro-dendritic connections between motoneurons in the rat spinal cord: an electron microscopic investigation. Brain Res 779:342-345.

Walton KD, Navarette R (1991) Postnatal changes in motoneurone electrotonic coupling studied in the in vitro rat lumbar spinal cord. J Physiol (Lond) 433:283-305.

Wu W (1996) Potential roles of gene expression change in adult rat spinal motoneurons following axonal injury: a comparison among c-jun, off-affinity nerve growth factor receptor (LNGFR), and nitric oxide synthase (NOS). Exp Neurol 141:190-200.

Zhang JT, Nicholson BJ (1989) Sequence and tissue distribution of a second protein of hepatic gap junctions, $\mathrm{Cx} 26$, as deduced from its cDNA. J Cell Biol 109:3391-3401. 